\title{
Countermeasures to Further Develop the Advanced Manufacturing Industry in Wuhan under "Internet +"
}

\author{
Zhi-Hong LI ${ }^{1}$, Ding-Bang WU ${ }^{2}$ \\ ${ }^{1}$ Business School, Jiang Han University, Wuhan, Hubei, P.R.China, 430056, China \\ ${ }^{2}$ School of Art and Design, Hankou University, Wuhan, Hubei, P.R.China, 430212, China \\ Email: ${ }^{a} 466828109 @ q q . c o m,{ }^{b}$ linanwudingbang@163.com
}

Keywords: "Internet +", Advanced manufacturing industry, Wuhan.

\begin{abstract}
The further development of the advanced manufacturing industry can't be separated away from the support of "Internet + ". To develop the advanced manufacturing industry more efficiently under "internet +"in Wuhan, the paper first analyzes the actual situation in developing the advanced manufacturing industry and explores the influence of "internet + " on the manufacturing industry. Then, by adopting the SWOT analysis approach, the paper expounds the strength, weak, opportunity and threat to further upgrade the advanced manufacturing industry under "internet +" in Wuhan. Finally, some correspondent countermeasures in developing the advanced manufacturing industry in Wuhan have been put forward.
\end{abstract}

\section{Actual Situation of the Advanced Manufacturing Industry in Wuhan}

\section{Connotation of the Advanced Manufacturing Industry}

The advanced manufacturing industry refers to the sector in which the manufacturing industry keeps integrating the hi-tech outcomes in electronic information, computers, mechanics, materials and modern management into new fields or applying these outcomes in its $\mathrm{R} \& \mathrm{D}$, design, production, on-line inspection, marketing service and management so as to realize a high efficiency, low consumption, clean and agile production and to achieve better economic and social effects. In view of process, the progressiveness lies in industries, technology and management. As for the sector, on the one hand, the traditional manufacturing industry like automobiles, equipment, steels, textile, food, petrol processing and electric machinery, etc should be upgraded. On the other hand, the emerging industry like high-end equipment manufacturing, biology, new energy cars and electronic information, etc ought to be cultivated. So, the advanced manufacturing industry has the features of top in industry, progressiveness in technology, up-to-date in management and innovation in mode, etc.

Some researchers think that the advanced manufacturing industry includes two levels: advanced manufacturing industry I and advanced manufacturing industry II. The former means the industrial forms based on information technology, biological technology, new materials and new energies, etc., such as biological pharmacy, optic fiber and so on. The latter refers to the traditional manufacturing industry reformed with the advanced technologies in information, biology, new materials and new energies. At present, the advanced manufacturing industry I occupies over $60 \%$ of the whole advanced manufacturing industry in the advanced countries.

The advanced manufacturing industry has two orientations: hi-tech-type manufacturing and service-type manufacturing. Namely, by massively utilizing the frontier advanced technologies in information, biology, new materials and new energies, the hi-tech industry will be derived and the traditional manufacturing industry will be upgraded. Meanwhile, new operational production model and commercial service mode will be formed during the value creation and realization of the advanced manufacturing industry in market investigation, R\&D design, inner management, after-sale services, users' feedback, circulation field and assistant productive service. 


\section{Actual Situation of the Advanced Manufacturing Industry in Wuhan}

The manufacturing industry in Wuhan mainly consists of energy and environmental protection, biological medicine, textile clothing, construction materials, automobile and parts, food and cigarette, light industry, electronic information, equipment, petrol chemicals, steel and deep processing, etc. These industries remain lagged behind in developing and using the hi-tech. As for the energy and environmental industry, coal, electricity, gas and petrol are still the main consumer goods in Wuhan. In 2010, the sum of these four energies accounts for $88.74 \%$ of the total.

In light of the electronic information industry, its products still focus on processing those with low added-value like monitors and air-conditioners. Also, its exports of outcomes are mainly on processing trade with weak competition and easily affected by the fluctuation of the international market, for example, in 2012, some enterprises saw a drop of 18.1 percentage points because of the reduction of international orders [1].

As for the bio-medicine industry, the industrial size in Wuhan is less than 1/10 of Shanghai, 1/6 of Shijiazhuang and 1/2 of Chengdu. In the products, new medicine with high added value is still insufficient. Besides, the R\&D inputs occupy only $4 \%$ of the sales volume, far below those of the international medicine industry that are usually $15 \%$ to $25 \%$. All these lead to an insufficiency of the sustainable competency.

Seen from the above-said situation, the hi-tech industry in Wuhan is still in a low level.

Although the traditional industries like automobiles and parts, equipment and steel and deep processing have been developed to some degree in integrating with the hi-tech and the service sector, the integration of the manufacturing industry with the logistics industry is in the initial level and that with the hi-tech is a little better. The information transmission, computer service and software haven't been well integrated into transportation, storage and postage sectors of the logistics sector. The lack of the support of the information technology in the logistics fields makes it unable to satisfy the needs of the advanced manufacturing industry in Wuhan. So, the advanced manufacturing industry II in Wuhan still lies in the mid-low level [2].

\section{Influence of "Internet +" on the Advanced Manufacturing Industry}

The fast development of "Internet + " has left a thorough effect on the productive mode, the industrial organizational forms and the industrial structure.

\section{Reform of the Productive Mode}

"Internet + " has accelerated the reform of the productive mode and the smart production has become a new type of production model. By internet, real time information interaction among the machine operation, workshop delivery, production and the demands in the market has been realized precisely. The industrial cloud platform has supplied the resources support and service guarantee for the productive and operational activities and the industrial productive elements have been optimized and high efficiently arranged. The big industrial data will go through the whole process of design, manufacturing, marketing and service.

\section{Innovation of the Industrial Organization}

"Internet + " has made the industrial organization structure networked and downsized. The network enterprise or the virtual enterprise which has only operational headquarters appears. The professional and synergy production is the main productive mode. The internet platform has contributed the massive business outsource. Also, e-commerce makes the marketing channel available in the internet, which expands the sales market and reduces the sales costs. Integration of the supply chain makes every enterprise become a node of the information system. Different enterprises can be arranged consistently through the network system in their raw material supply, machine operation and production. The upstream and downstream of the industrial chain can be cooperative by way of network and real time. 


\section{Upgrading the Industrial Structure}

"Internet +" has upgraded the industrial structure progressively and it is the tendency to make the manufacturing industry service-typed. Concretely, service-typed manufacturing industry has three forms: one is the information service in which the industrial enterprises carry out the remote operation and maintenance by internet. Another is that the professional information service firms in information consultation, development and integration, operation and services etc have been derived during applying the internet. Then, new-typed information service firms like mass-outsource, mass-design and industrial e-commerce, etc have been born by way of the internet platform and they are specialized in supplying R\&D design, operational management and marketing and so on.

\section{Reform the Industrial Innovation Mode}

"Internet + " has made the industrial innovation changed thoroughly and the synergy innovation has become its new mode. The trans-regional, network synergy innovation platforms have been established by integrating governments, enterprises and industrial associations. For example, the industrial 4.0 plan in German is one of the successful cases [3].

\section{SWOT Analysis of the Advanced Manufacturing Industry in Wuhan under "Internet +"}

According to the features of "Internet +" and the actual situation of the advanced manufacturing industry in Wuhan, the strength, weak, opportunity and threat (short form: SWOT) co-exist to further develop the advanced manufacturing industry of Wuhan(see Table 1). SWOT is a systematic analysis method based on the inner strength and weak and on the outer opportunity and threat of the research object. We can draw some correspondent conclusions by using it.

Table 1 SWOT analysis to develop the advanced manufacturing industry in Wuhan

\begin{tabular}{|c|c|}
\hline Strength & Weak \\
\hline $\begin{array}{l}\text { Self-contained industrial system } \\
\text { Successively growing industrial size } \\
\text { Technological levels being raised } \\
\text { Manufacturing industrial chain being improved }\end{array}$ & $\begin{array}{l}\text { Independent innovative capacity insufficient } \\
\text { Core competitive competency to be } \\
\text { strengthened } \\
\text { Traditional industries dominating } \\
\text { Productive service sector lagging behind }\end{array}$ \\
\hline Opportunity & Threat \\
\hline $\begin{array}{l}\text { Main features of "Internet +" like } \\
\text { network-typed, digital and cloud intelligence } \\
\text { [4] requiring a highly integration of } \\
\text { manufacturing industry and service sector. } \\
\text { Thus, the thoroughly change of the productive } \\
\text { element arrangement will bear numerous } \\
\text { chances for the enterprises. } \\
\text { Also, the low-cost resources arrangement mode } \\
\text { based on the internet has given multiple } \\
\text { chances for the mid-small firms. }\end{array}$ & $\begin{array}{l}\text { The actual situation of the advanced } \\
\text { manufacturing industry in Wuhan,namely, the } \\
\text { above-said weakness, the hi-tech industry still } \\
\text { being in a low level and the reform of the } \\
\text { traditional manufacturing industry being in } \\
\text { mid-low levels, makes it obliged to overcome } \\
\text { many difficulties for the advanced } \\
\text { manufacturing industry to make a good use of } \\
\text { the chances brought by "Internet +". }\end{array}$ \\
\hline
\end{tabular}

\section{How to Further Develop the Advanced Manufacturing Industry in Wuhan under "Internet +" \\ Deepening the Integration between the Internet and the Manufacturing Industry}

First, on the base of the existent industrial system like automobiles, equipment, electronic information, etc in Wuhan, strengthen the construction of the industrial internet and foster new models of the industrial internet in intelligent inspection and the trace of the whole industrial chain. 
Then, new-typed manufacturing mode like personified customer-made, mass-outsource design, and smart making, etc based on internet should be explored. By mixing the internet firms and the manufacturing enterprises, an open industrial form system of complementary advantages and of cooperative double wins will be built [5].

\section{New-Typed Industrial Organization should be Set Up}

New-typed industrial organization which is based on the customer's participation, platform service, open and sharing ought to be built so as to create low-cost, facilitation, total-factor and open network space and resources sharing channels in R\&D design, production, management and marketing,etc. The manufacturing enterprises are encouraged to use mobile e-commerce and customization on line,etc and the virtual firms to be formed.

\section{Manufacturing Enterprises to be Transformed Service-Typed}

The industrial chain of the manufacturing enterprises should be extended toward the service section like on-line supervision, financing lease and supply chain finance,etc. The information technology service sector should focus on the manufacturing industry so as to consolidate the project design and synthetic integration capacity. The productive service sectors like the third party logistics, energy saving and environmental protection, inspection and certification, e-commerce, service outsourcing, professional finance and training,etc are to be greatly developed so that the business cooperation process should be innovated and that the whole efficiency of the industrial chain be raised.

\section{The Innovative System of the Manufacturing Industry to be Further Improved}

The general issues of innovation for the manufacturing industry can be solved conjointly by governments, social capitals, and industrial innovative strategic alliance of enterprises, universities and research institutes. Meanwhile, the information inspection institutions should be formulated in order to strengthen the network security ability, safeguard the safety of products, service and supply chain and so forth.

\section{Acknowledgment}

The paper is funded by Research Center on the Development of the Manufacturing Industry of the Wuhan City Circle, China(wz2015y21), by Wuhan Studies Institute,Hubei, China(jhunwyy2015214), by Key Discipline of Hubei Province in Management Science and Engineer.

\section{References}

[1] http://www.whec.gov.cn/

[2] Zhihong Li, Willian A. Peek, Tenpao Lee. The Correlation Between the Circulation Sector and The Economy in Wuhan. International Journal of Business Strategy, Volume 14, No.1, 2014.

[3] "Internet +": New Engine of Strengthening by Manufacturing. Study Timely Journal, April 13, 2015

[4] Huaiqiao Ying. Outlook in the Times of "Cloud Intelligence": from "Instruments Made by Software" to "All Made by Software". Electronic Measuring Technology in Foreign Countries. No.1, 2013

[5] http://www.hbeitc.gov.cn/ 